\title{
Discrepancies of Implicit and Explicit Self-Esteem as Predictors of Attributional Bias and Paranoia
}

\author{
You Jin Park', Jin Young Park ${ }^{2,3}$, Kyung-Mi Chung ${ }^{2,3}$, Yul-Mai Song ${ }^{4}$, and Kyungun Jhung ${ }^{1 凶}$ \\ ${ }^{1}$ Department of Psychiatry, Catholic Kwandong University College of Medicine, International St. Mary's Hospital, Incheon, Republic of Korea \\ ${ }^{2}$ Department of Psychiatry, Gangnam Severance Hospital, Yonsei University Health System, Seoul, Republic of Korea \\ ${ }^{3}$ Department of Psychiatry and Institute of Behavioral Science in Medicine, Yonsei University College of Medicine, Seoul, Republic of Korea \\ ${ }^{4}$ Department of Education, National Center for Mental Health, Seoul, Republic of Korea
}

\begin{abstract}
Objective The current study aimed to examine the association of implicit self-esteem, explicit self-esteem and their interaction with paranoia and attributional bias. The relationship of the size and the direction of the discrepancy between implicit and explicit self-esteem with paranoia and attributional bias was examined.

Methods A total of 128 female college students participated. We administered the Implicit Association Test to assess implicit self-esteem, and the Rosenberg Self-Esteem Scale to measure explicit self-esteem. Paranoia Scale was used, and the attributional bias was assessed using the Ambiguous Intentions Hostility Questionnaire.

Results Results showed that explicit but not implicit self-esteem was negatively associated with paranoia, blame bias and hostility perception bias in ambiguous situations. The interaction of implicit and explicit self-esteem was associated with hostility perception in ambiguous situations. As for the discrepancy, the size of the discrepancy between implicit and explicit self-esteem was positively associated with hostility perception in ambiguous situations. Moreover, the direction of the discrepancy was specifically relevant: damaged self-esteem (high implicit and low explicit self-esteem) was associated with increased levels of paranoia, blame bias and hostility perception in ambiguous situations.

Conclusion These findings provide new insights into the role of the implicit and explicit self-esteem in attributional bias and paranoia and point to damaged self-esteem as a possible vulnerability marker for illogical attribution of blaming others and perceiving hostility in social situations.

Psychiatry Investig 2019;16(3):185-192
\end{abstract}

Key Words Implicit self-esteem, Explicit self-esteem, Self-esteem discrepancy, Attributional bias, Paranoia.

\section{INTRODUCTION}

In life, we as human beings endlessly communicate with the world around us. In this process, individuals try to understand the meaning and the reasons underlying the occurring events. An attributional style of an individual determines how one assigns the causality of outcomes in such events. The attribution style refers to the pervasive pattern in generating causal explanations for outcomes in such events. Paranoid patients are known to show a greater tendency to

Received: October 8, 2018 Revised: November 30, 2018

Accepted: December 24, 2018

$\triangle$ Correspondence: Kyungun Jhung, MD, PhD

Department of Psychiatry, Catholic Kwandong University College of Medicine, International St. Mary's Hospital, 25 Simgok-ro 100gil, Seo-gu, Incheon 22711, Republic of Korea

Tel: +82-32-290-3878, Fax: +82-32-290-3879, E-mail: kyungun12@gmail.com

(a) This is an Open Access article distributed under the terms of the Creative Commons Attribution Non-Commercial License (https://creativecommons.org/licenses/bync/4.0) which permits unrestricted non-commercial use, distribution, and reproduction in any medium, provided the original work is properly cited. blame others for negative outcomes. ${ }^{1,2}$ Individual with a biased attributional style may be predisposed to one of the major psychopathologies, the formation of persecutory delusions.

The aspects of the self have been reported to serve as accounting factors for attributional bias. Self-esteem, defined as a holistic assessment of one's own values with a positive or negative orientation toward oneself, ${ }^{3}$ has shown to be associated with abnormal reasoning. Early theorists proposed that paranoia serves a defensive function. Bentall and colleagues ${ }^{4}$ posited that individuals with paranoia make causal attributions of negative self-referent events to others, thus proposing a model of positive explicit self-esteem and negative implicit self-esteem. ${ }^{5}$ On the other hand, Freeman et al. ${ }^{6}$ suggested paranoia to be built on negative self-views and associated emotional process, predicting both low explicit and implicit self-esteem in those with paranoia. However, following studies in the clinical population did not yield to support these hypothesized models. While previous studies generally agree 
that patients with paranoia show more negative explicit selfesteem than controls, ${ }^{7}$ findings have been far more inconsistent on implicit self-esteem. Studies including that of Moritz et al. ${ }^{8}$ showed a relatively low implicit self-esteem in patients with paranoia, ${ }^{9,10}$ while others reported parallel implicit selfesteem to that of controls. ${ }^{11,12}$

A recent initiative of the Research Domain Criteria ${ }^{13} \mathrm{em}-$ phasizes a shift in the research framework from investigating illness as a categorically separate entity to investigating symptoms on a dimensional level that span from healthy, to subclinical, to clinical levels. Paranoia has been extensively studied in psychiatric illnesses such as schizophrenia, but it has also been reported in the general population with a prevalence of approximately $10-15 \% .{ }^{14}$ In a recent study, Klein et al. ${ }^{15}$ reported increased subclinical paranoia to be associated with attributional bias, similar to the findings of previous studies in schizophrenia patients. ${ }^{16,17}$ Studies such as that of Klein et al., ${ }^{15}$ examining paranoia on a continuum, may provide valuable information regarding the shared deficits or distinct characteristics that define clinical and subclinical presentation of paranoia.

More recently, it has been suggested that not only the level of each self-esteem but also the discrepancy between the two may be the source of psychological problems, including paranoia. To directly assess the discrepancy, Vásquez et al. ${ }^{18}$ compared z-transformed levels of explicit and implicit self-esteem and reported no self-esteem discrepancy in patients with delusions. However, the validity of the task (Self-Referent Incidental Recall Task) used for implicit measure of selfesteem was questionable in this study. In a different study, schizophrenia patients with non-self-blaming paranoia showed the discrepancy between explicit and implicit selfesteem. ${ }^{19}$ Differences between previous findings may result from measures used for implicit self-esteem, as the latter study used the Implicit Association Test (IAT), considered the most appropriate measure of implicit self-esteem..$^{20}$ Furthermore, the size and the direction of the discrepancy and the interaction between them may also provide important information. Self-esteem discrepancies may be distinguished to two forms according to its direction: high implicit with low explicit self-esteem, termed the damaged self-esteem, ${ }^{21}$ and low implicit with high explicit self-esteem, termed the fragile self-esteem ${ }^{22}$ or the defensive self-esteem. ${ }^{23}$

Using the IAT, the current study aimed to examine whether implicit self-esteem, explicit self-esteem and their interaction are associated with paranoia and attributional bias in subclinical paranoia, to determine if similar or distinct pattern of deficits are present in the nonclinical population. Furthermore, we investigated the main effects of the size and the direction of the discrepancy between implicit and explicit self-esteem, as well as the interaction between these measures, to attributional bias and subclinical paranoia.

\section{METHODS}

\section{Participants}

Total of 128 participants were recruited. Participants were female nursing college students who visited Gongju National Hospital for training or practice. All participants volunteered to participate in the study. Those with any past or current psychiatric diagnosis or treatment were excluded. Written informed consent was obtained from all participants. The study was reviewed and approved by the Institutional Review Board of Gongju National Hospital (2010-09).

\section{Measures}

\section{Explicit self-esteem}

Explicit self-esteem was assessed using the Rosenberg SelfEsteem Scale (RSES), ${ }^{3}$ which is a widely used self-report measure of one's global feeling of worthiness as a human being. ${ }^{24}$ The scale is consisted of 10 items, with five positively worded and five negatively worded items. Ratings are based on a 4point scale (1-strongly disagree to 4 -strongly agree). Cronbach's a reliability coefficient was calculated to identify internal consistency reliability for verifying the reliability of Korean version of the RSES. The reliability coefficient ranged between 0.75 and $0.87 .{ }^{25}$ Higher RSES scores were considered to reflect higher levels of explicit self-esteem.

\section{Implicit self-esteem}

Implicit self-esteem was assessed using the IAT. Individuals are instructed to categorize the stimuli according to automatic associations on concept discrimination between self-relevant and non-self-relevant words and attribute discrimination between positive and negative words. ${ }^{26}$ Reaction time measures reflect the relative strength of these implicit associations. ${ }^{27}$ Pronouns were used as in previous studies for self vs. nonself dimension, ${ }^{28,29}$ to avoid semantic associations that may be prompted by nouns. ${ }^{30,31}$ Self-relevant pronouns were 'I, me, my, mine, and self', and non-self-relevant or other pronouns were 'they, them, their, it, and other. ${ }^{32}$ Word stimuli for the attribute discrimination consisted of a set of adjectives describing 10 positive and 10 negative personal attributes. Selected adjectives are from a previous study of IAT using the Korean language (freedom, health, happiness, praise, stability, satisfaction, love, peace, kindness, and smile, as the positive word stimuli; abuse, grief, insult, hatred, tragedy, violation, poverty, crash, death, and decomposition, as the negative word stimuli). ${ }^{33}$ Target word stimuli were presented as black letters in 
the center of a computer screen on a gray background. Participants were directed to assign target words as quickly as possible to their associating category by pressing a computer key. In the self-positive task, participants were instructed to press a certain key when presented with the 'self' or the 'positive' stimuli vs. a certain different key when presented with the 'other' or 'negative' stimuli. In the self-negative task, participants were directed to press a certain key for the 'self' or 'negative' stimuli and a certain different key for the 'other' and 'positive' stimuli. The logic of the IAT is that response latency will be shorter when two associated categories are assigned to the same key than when two less associated (or non-associated) categories are assigned to the same key. For example, shorter reaction time in the self-positive task compared with the self-negative task reflects higher positive implicit self-esteem. ${ }^{32,34,35}$ The IAT is a valid and reliable tool for measuring the implicit self-esteem, used widely in past research. ${ }^{26,36}$

\section{Paranoia}

The Paranoia Scale ${ }^{37}$ measures nonclinical paranoid ideation that results from everyday experiences. Although the scale was not originally made for diagnostic use, it has also been widely used in clinical samples. The scale consists of 20 items, scored on a $0-4$ Likert scale, from 'not at all' to 'always'. Higher score reflects higher levels of nonclinical paranoia. The Cronbach's a was 0.90 in the present sample.

\section{Attributional bias}

The attributional bias of an individual was assessed by the Ambiguous Intentions Hostility Questionnaire (AIHQ). ${ }^{38}$ The AIHQ is a measure sensitive to hostile social cognitive biases with indices for hostility bias, attribution of blame, and the tendency for aggressive response in situations. The scale is comprised of 15 hypothetical negative situations with varying levels of intentionality: 5 accidental (e.g., "You're dancing at a club and someone bumps into you from behind."), 5 ambiguous (e.g." "You walk past a bunch of teenagers at a mall and you hear them start to laugh."), and 5 intentional (e.g., "Your neighbors are playing loud music. You knock on the door and ask them to turn it down. Fifteen minutes later, the music is loud again.") situations. During the assessment, participants were first asked to imagine the scenario happening to them. Next, they were asked to write down the reason that others acted that way. Three parameters of hostility perception bias, aggressive response bias and composite blame bias are extracted. The hostility perception and aggressive response indices are rated by the rater, on a scale from 1 to 5 ("not at all hostile" to "very hostile" and "not at all aggressive" to "very aggressive", respectively). The composite blame score (range $1-5$ ) is an average score of the ratings on the intent (the de- gree to which the other person committed the act on purpose; range 1-6), anger (how angry the situation would make subject feel; range 1-5), and blame (the degree to which how much an individual blames the others for the negative outcome; range 1-5). The Korean version of the AIHQ has been shown to have good inter-rater reliability for both the hostility perception bias (intra-class correlation: $0.84-0.93$ ) and the aggressive response bias $(0.71-0.88){ }^{39}$ The internal consistency (Cronbach's alpha) of composite blame bias score in the present study were found to be $0.83-0.87$ across all situations.

\section{Data analyses}

To examine the relationship of implicit and explicit selfesteem to paranoia and attributional biases, a series of hierarchical multiple regression analyses were performed with explicit self-esteem and implicit self-esteem entered in step 1 and their interaction in step 2. The interactions were tested according to the procedure proposed by Aiken et al. ${ }^{40}$ All variables were centered before being entered into the equation. The relationship of the discrepancy between implicit and explicit self-esteem to paranoia and attributional bias was also tested. For determining the size of the discrepancy, the absolute value of the difference between the standardized explicit and implicit self-esteem scores were computed. Higher score indicates a larger discrepancy between the implicit and explicit self-esteem. For the direction of the discrepancy, 61 subjects had higher implicit than explicit self-esteem, and 67 subjects had higher explicit than implicit self-esteem in the present study. A variable indicating the direction of the discrepancy was generated (implicit>explicit; damaged self-esteem or implicit<explicit; fragile self-esteem; dummy code). We tested whether the discrepancy between implicit and explicit self-esteem is related to paranoia and attributional bias by conducting a series of hierarchical multiple regression analyses with the size and the direction of the discrepancy entered in step 1 and their interaction entered in step 2. The discrepancy score (the size of the discrepancy) was centered before being entered into the equation. This method of using the discrepancy score, the dummy variable and their interaction has shown to be useful in testing the relative difference between implicit and explicit measures..$^{21,41}$

\section{RESULTS}

\section{Demographics and descriptive statistics}

Demographics and the descriptive statistics of all study variables are presented in Table 1. Mean age of the subjects was 21.1 years $(\mathrm{SD}=2.38$, range $=19-30)$. The intercorrelations among the study measures are displayed in Table 2 . The measures of implicit and explicit self-esteem were not corre- 
lated with each other. Explicit self-esteem negatively correlated with paranoia, as well as blame and hostility perception scores in ambiguous situations. Implicit self-esteem was uncorrelated with any other variables.

\section{Associations of implicit and explicit self-esteem with paranoia and attributional bias}

Hierarchical multiple regression analyses were conducted to test the association of explicit and implicit self-esteem with paranoia and attributional bias. The results of step 1 showed a negative association of explicit self-esteem with paranoia $(\beta=-0.52, \mathrm{p}<0.001)$, blame scores $(\beta=-0.32, \mathrm{p}<0.001)$ and hostility perception scores $(\beta=-0.34, \mathrm{p}<0.001)$ in ambiguous

Table 1. Demographics and descriptive statistics

\begin{tabular}{lc}
\hline \multicolumn{1}{c}{ Variables } & Mean (SD) \\
\hline Age (years) & $21.18(2.38)$ \\
Implicit self-esteem & $0.55(0.02)$ \\
Explicit self-esteem & $30.35(5.14)$ \\
Paranoia & $19.17(11.63)$ \\
AIHQ & \\
Blame-ambiguous & $2.68(0.73)$ \\
Blame-intentional & $3.73(0.69)$ \\
Blame-accidental & $2.00(0.56)$ \\
Hostility-ambiguous & $1.87(0.42)$ \\
Hostility-intentional & $2.45(0.43)$ \\
Hostility-accidental & $1.16(0.19)$ \\
Aggression-ambiguous & $1.76(0.33)$ \\
Aggression-intentional & $2.17(0.47)$ \\
Aggression-accidental & $1.60(0.33)$ \\
\hline
\end{tabular}

SD: standard deviation, AIHQ: Ambiguous Intentions Hostility Questionnaire $^{38}$ situations. There was no significant association of implicit self-esteem with paranoia $(\beta=0.10, p=0.178)$ nor any of the variables of the AIHQ (all $\mathrm{p}>0.05$ ).

\section{Associations of the interaction between implicit and explicit self-esteem with paranoia and attributional bias}

Table 3 shows the results of the multiple hierarchical regression analyses after entering the interaction between the implicit and explicit self-esteem into step 2. The results showed no significant association of the interaction between implicit and explicit self-esteem with paranoia $(\beta=-0.04, p=0.577)$. For the attributional bias, the interaction between implicit and explicit self-esteem associated significantly with only the hostility perception bias in ambiguous situations $(\beta=-0.16, \mathrm{p}<$ $0.05)$, but not with any of the other variables of the AIHQ. Figure 1 presents the predicted values of the hostility perception bias for the interaction between implicit and explicit selfesteem. Comparison of the slopes of the regression lines representing low (-1 SD) and high explicit self-esteem (+1 SD) showed that the association between implicit self-esteem and hostility perception bias in ambiguous situations is stronger when the participants had low explicit self-esteem.

\section{Associations of the discrepancy between implicit and explicit self-esteem with paranoia and attributional bias}

Table 4 shows the results of the multiple hierarchical regression analyses to test whether the size of the discrepancy, the direction of the discrepancy and their interaction relates to paranoia and attributional bias. The results of step 1 showed that the size of the discrepancy was positively related to hostility perception bias in ambiguous situations $(\beta=0.20, \mathrm{p}<$

Table 2. Correlations among measures of implicit and explicit self-esteem, paranoia and attributional bias

\begin{tabular}{|c|c|c|c|c|c|c|c|c|c|c|c|c|}
\hline & 1 & 2 & 3 & 4 & 5 & 6 & 7 & 8 & 9 & 10 & 11 & 12 \\
\hline 1. Implicit self-esteem & - & & & & & & & & & & & \\
\hline 2. Explicit self-esteem & 0.12 & - & & & & & & & & & & \\
\hline 3. Paranoia & 0.03 & $-0.51^{\dagger}$ & - & & & & & & & & & \\
\hline 4. Blame-ambiguous & 0.05 & $-0.31^{\dagger}$ & $0.36^{+}$ & - & & & & & & & & \\
\hline 5. Blame-intentional & -0.01 & -0.16 & $0.30^{\dagger}$ & $0.58^{\dagger}$ & - & & & & & & & \\
\hline 6. Blame-accidental & -0.16 & -0.09 & $0.26^{\dagger}$ & $0.56^{\dagger}$ & $0.41^{\dagger}$ & - & & & & & & \\
\hline 7. Hostility-ambiguous & 0.09 & $-0.32^{\dagger}$ & $0.37^{\dagger}$ & $0.64^{\dagger}$ & $0.46^{\dagger}$ & 0.17 & - & & & & & \\
\hline 8. Hostility-intentional & 0.03 & -0.08 & $0.18^{*}$ & $0.33^{+}$ & $0.54^{\dagger}$ & $0.19^{*}$ & $0.46^{\dagger}$ & - & & & & \\
\hline 9. Hostility-accidental & 0.02 & -0.16 & $0.28^{\dagger}$ & $0.18^{*}$ & 0.09 & 0.16 & 0.15 & 0.15 & - & & & \\
\hline 10. Aggression-ambiguous & 0.02 & -0.17 & $0.22^{*}$ & $0.44^{\dagger}$ & $0.42^{\dagger}$ & $0.25^{\dagger}$ & $0.36^{\dagger}$ & $0.29^{\dagger}$ & $0.22^{\dagger}$ & - & & \\
\hline 11. Aggression-intentional & -0.08 & 0.03 & -0.00 & $0.17^{*}$ & $0.49^{\dagger}$ & 0.16 & $0.19^{*}$ & $0.42^{\dagger}$ & 0.01 & $0.29^{\dagger}$ & - & \\
\hline 12. Aggression-accidental & -0.08 & 0.02 & 0.13 & $0.19 *$ & $0.25^{\dagger}$ & $0.51^{\dagger}$ & 0.09 & 0.15 & $0.20^{*}$ & $0.26^{\dagger}$ & $0.29^{\dagger}$ & - \\
\hline
\end{tabular}

${ }^{*} \mathrm{p}<0.05,{ }^{\dagger} \mathrm{p}<0.01$ 
Table 3. Hierarchical multiple regression analysis: associations of explicit self-esteem, implicit self-esteem and the interaction between implicit and explicit self-esteem with paranoia and attributional bias

\begin{tabular}{|c|c|c|c|c|c|c|c|c|c|}
\hline & \multicolumn{6}{|c|}{ Step 1} & \multirow{2}{*}{\multicolumn{3}{|c|}{$\begin{array}{c}\text { Step } 2 \\
\text { Implicit SE } \times \text { Explicit SE }\end{array}$}} \\
\hline & \multicolumn{3}{|c|}{ Implicit SE } & \multicolumn{3}{|c|}{ Explicit SE } & & & \\
\hline & B & $\mathrm{SE}$ & $\beta$ & $\mathrm{B}$ & $\mathrm{SE}$ & $\beta$ & $\mathrm{B}$ & SE & $\beta$ \\
\hline Paranoia & 4.72 & 3.48 & 0.10 & -1.19 & 0.17 & $-0.52^{\dagger}$ & -0.41 & 0.73 & -0.04 \\
\hline \multicolumn{10}{|l|}{ Blame } \\
\hline Ambiguous & 0.27 & 0.24 & 0.09 & -0.04 & 0.01 & $-0.32^{\dagger}$ & 0.00 & 0.05 & 0.01 \\
\hline Intentional & 0.00 & 0.24 & 0.00 & -0.02 & 0.01 & -0.17 & 0.03 & 0.05 & 0.06 \\
\hline Accidental & -0.35 & 0.19 & -0.15 & -0.00 & 0.01 & -0.07 & 0.02 & 0.04 & 0.05 \\
\hline \multicolumn{10}{|l|}{ Hostility } \\
\hline Ambiguous & 0.22 & 0.14 & 0.13 & -0.02 & 0.00 & $-0.34^{\dagger}$ & -0.05 & 0.02 & $-0.16^{*}$ \\
\hline Intentional & 0.07 & 0.15 & 0.04 & -0.00 & 0.00 & -0.09 & -0.05 & 0.03 & -0.14 \\
\hline Accidental & 0.03 & 0.06 & 0.04 & -0.00 & 0.00 & -0.17 & 0.00 & 0.01 & -0.00 \\
\hline \multicolumn{10}{|l|}{ Aggression } \\
\hline Ambiguous & 0.05 & 0.11 & 0.04 & -0.01 & 0.00 & -0.17 & -0.00 & 0.02 & -0.01 \\
\hline Intentional & -0.16 & 0.16 & -0.09 & 0.00 & 0.00 & 0.04 & -0.03 & 0.03 & -0.08 \\
\hline Accidental & -0.17 & 0.17 & -0.09 & 0.00 & 0.00 & 0.03 & 0.03 & 0.03 & 0.08 \\
\hline
\end{tabular}

Paranoia $\mathrm{R}^{2}=0.27$ in step1 $(\mathrm{p}<0.001) ; \Delta \mathrm{R}^{2}=0.00$ in step2 $(\mathrm{p}=0.577)$; Blame Ambiguous $\mathrm{R}^{2}=0.10$ in step1 $(\mathrm{p}=0.001) ; \Delta \mathrm{R}^{2}=0.00$ in step2 $(\mathrm{p}=$ $0.876)$; Intentional $R^{2}=0.02$ in step1 ( $\left.p=0.162\right) ; \Delta R^{2}=0.00$ in step2 ( $\left.p=0.492\right) ;$ Accidental $R^{2}=0.03$ in step1 ( $\left.p=0.113\right) ; \Delta R^{2}=0.00$ in step2 ( $\left.p=0.546\right)$; Hostility Ambiguous $\mathrm{R}^{2}=0.12$ in step1 $(\mathrm{p}<0.001) ; \Delta \mathrm{R}^{2}=0.02$ in step2 $(\mathrm{p}=0.046)$; Intentional $\mathrm{R}^{2}=0.00$ in step1 $(\mathrm{p}=0.567) ; \Delta \mathrm{R}^{2}=0.01$ in step2 $(\mathrm{p}=0.118) ;$ Accidental $\mathrm{R}^{2}=0.03$ in step1 $(\mathrm{p}=0.147) ; \Delta \mathrm{R}^{2}=0.00$ in step2 $(\mathrm{p}=0.975) ;$ Aggression Ambiguous $\mathrm{R}^{2}=0.03$ in step1 $(\mathrm{p}=0.139) ; \Delta \mathrm{R}^{2}=0.00$ in step2 ( $\mathrm{p}=0.906)$; Intentional $\mathrm{R}^{2}=0.01$ in step1 ( $\left.\mathrm{p}=0.550\right) ; \Delta \mathrm{R}^{2}=0.00$ in step2 ( $\left.\mathrm{p}=0.324\right)$; Accidental $\mathrm{R}^{2}=0.00$ in step1 ( $\left.\mathrm{p}=0.579\right) ; \Delta \mathrm{R}^{2}=0.00$ in step2 ( $\mathrm{p}=0.331) .{ }^{*} \mathrm{p}<0.05,{ }^{\dagger} \mathrm{p}<0.001$. Implicit SE: Implicit self-esteem ${ }^{26}$ Explicit SE: explicit self-esteem ${ }^{3}$

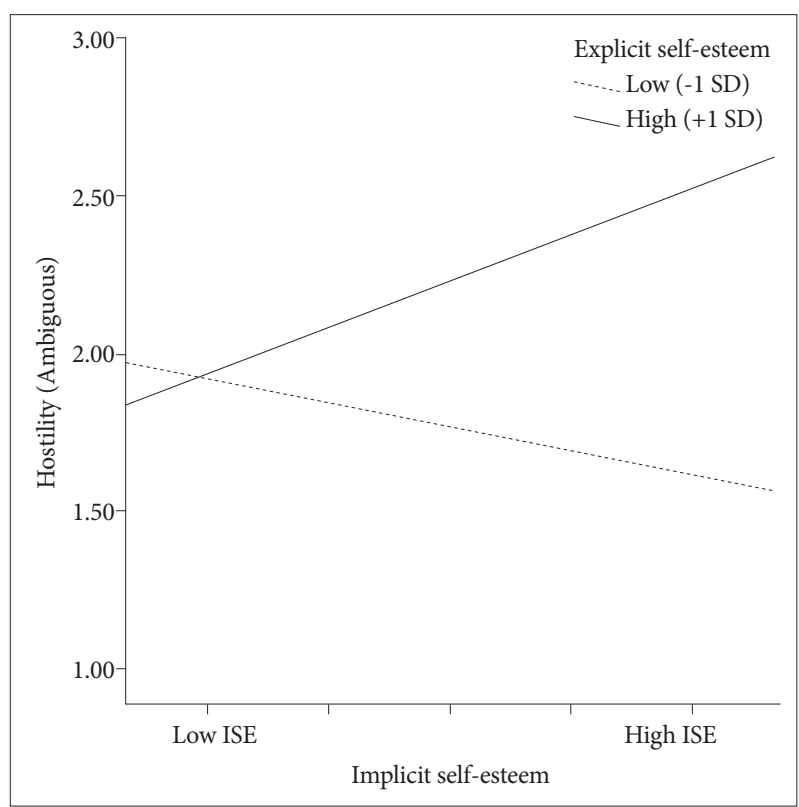

Figure 1. Predicted values for hostility perception bias in ambiguous situations, illustrating the interaction between implicit and explicit self-esteem. SD: standard deviation, ISE: implicit self-esteem.

0.05). No significant associations were found of the size of the discrepancy with any other AIHQ variables. The direction of the discrepancy was significantly related to paranoia $(\beta=$ $0.03, \mathrm{p}<0.001)$, blame bias in ambiguous situations $(\beta=0.28$, $\mathrm{p}<0.01)$ and hostility perception bias in ambiguous situations $(\beta=0.34, p<0.001)$. No other associations were found for the direction of the discrepancy with any of the other AIHQ variables. In addition, the results of step 2 showed that the interaction between the size and the direction of the discrepancy was significantly associated with paranoia $(\beta=0.51, \mathrm{p}<0.01)$. Results showed no significant associations of the interaction between the size and the direction of the discrepancy with the AIHQ variables. Figure 2 presents the predicted values for the interaction between the size of the discrepancy and the direction of the discrepancy with paranoia. Significant associations were found between the size of the discrepancy and paranoia in subjects with damaged self-esteem (higher implicit than explicit self-esteem). Subjects with fragile self-esteem (higher explicit than implicit self-esteem) showed no significant associations between the size of the discrepancy and paranoia.

\section{DISCUSSION}

The aim of this study was to investigate whether explicit self-esteem, implicit self-esteem and their interaction were associated with subclinical paranoia and attributional bias. The size and the direction of the discrepancy between the two selfesteems were also explored. Findings demonstrated that ex- 
Table 4. Hierarchical multiple regression analysis: associations of the size of the discrepancy, the direction of the discrepancy and the interaction between the size and the direction of the discrepancy with paranoia and attributional bias

\begin{tabular}{|c|c|c|c|c|c|c|c|c|c|}
\hline & \multicolumn{6}{|c|}{ Step 1} & \multirow{2}{*}{\multicolumn{3}{|c|}{$\begin{array}{c}\text { Step } 2 \\
\text { Size of discrepancy } \times \text { Direction of discrepancy }\end{array}$}} \\
\hline & \multicolumn{3}{|c|}{ Size of discrepancy } & \multicolumn{3}{|c|}{ Direction of discrepancy } & & & \\
\hline & B & SE & $\beta$ & B & SE & $\beta$ & B & SE & $\beta$ \\
\hline Paranoia & 0.18 & 0.13 & 0.11 & 8.65 & 1.91 & $0.037^{\ddagger}$ & 0.81 & 0.25 & $0.51^{\dagger}$ \\
\hline \multicolumn{10}{|l|}{ Blame } \\
\hline Ambiguous & 0.00 & 0.00 & 0.03 & 0.42 & 0.12 & $0.28^{\dagger}$ & 0.02 & 0.01 & 0.23 \\
\hline Intentional & 0.00 & 0.00 & 0.02 & 0.15 & 0.12 & 0.11 & 0.01 & 0.01 & 0.12 \\
\hline Accidental & -0.00 & 0.00 & -0.02 & 0.01 & 0.10 & 0.01 & -0.00 & 0.01 & -0.12 \\
\hline \multicolumn{10}{|l|}{ Hostility } \\
\hline Ambiguous & 0.01 & 0.00 & $0.20^{*}$ & 0.29 & 0.07 & $0.34^{\ddagger}$ & 0.00 & 0.01 & 0.11 \\
\hline Intentional & 0.00 & 0.00 & 0.11 & 0.13 & 0.00 & 0.15 & -0.01 & 0.01 & -0.17 \\
\hline Accidental & -0.00 & 0.00 & -0.04 & 0.05 & 0.03 & 0.13 & 0.00 & 0.00 & 0.18 \\
\hline \multicolumn{10}{|l|}{ Aggression } \\
\hline Ambiguous & -0.00 & 0.00 & -0.01 & 0.09 & 0.05 & 0.14 & 0.00 & 0.00 & 0.16 \\
\hline Intentional & 0.00 & 0.00 & 0.01 & -0.08 & 0.08 & -0.08 & -0.00 & 0.01 & -0.06 \\
\hline Accidental & -0.00 & 0.00 & -0.07 & -0.07 & 0.08 & -0.08 & 0.00 & 0.01 & -0.00 \\
\hline
\end{tabular}

Paranoia $\mathrm{R}^{2}=0.15$ in step1 $(\mathrm{p}<0.001) ; \Delta \mathrm{R}^{2}=0.06$ in step2 $(\mathrm{p}=0.002)$; Blame Ambiguous $\mathrm{R}^{2}=0.08$ instep1 $(\mathrm{p}=0.004) ; \Delta \mathrm{R}^{2}=0.01$ in step2 $(\mathrm{p}=$ $0.177)$; Intentional $\mathrm{R}^{2}=0.01$ in step1 ( $\left.\mathrm{p}=0.412\right) ; \Delta \mathrm{R}^{2}=0.00$ in step2 ( $\left.\mathrm{p}=0.492\right)$; Accidental $\mathrm{R}^{2}=0.00$ in step1 ( $\left.\mathrm{p}=0.947\right) ; \Delta \mathrm{R}^{2}=0.00$ in step2 $(\mathrm{p}=0.519) ;$ Hostility Ambiguous $\mathrm{R}^{2}=0.16$ step1 $(\mathrm{p}<0.001) ; \Delta \mathrm{R}^{2}=0.00$ in step2 $(\mathrm{p}=0.493)$; Intentional $\mathrm{R}^{2}=0.04$ in step1 $(\mathrm{p}=0.076) ; \Delta \mathrm{R}^{2}=0.00$ in step2 ( $\mathrm{p}=0.349)$; Accidental $\mathrm{R}^{2}=0.02$ in step1 $(\mathrm{p}=0.275) ; \Delta \mathrm{R}^{2}=0.00$ in step2 ( $\left.\mathrm{p}=0.323\right)$; Aggression Ambiguous $\mathrm{R}^{2}=0.02$ in step1 ( $\left.\mathrm{p}=0.272\right)$; $\Delta \mathrm{R}^{2}=0.00$ in step2 $(\mathrm{p}=0.383)$; Intentional $\mathrm{R}^{2}=0.00$ in step1 $(\mathrm{p}=0.619) ; \Delta \mathrm{R}^{2}=0.00$ in step2 $(\mathrm{p}=0.726)$; Accidental $\mathrm{R}^{2}=0.01$ in step1 ( $\left.\mathrm{p}=0.463\right)$; $\Delta \mathrm{R}^{2}=0.00$ in step2 $(\mathrm{p}=0.975) .{ }^{*} \mathrm{p}<0.05,{ }^{\dagger} \mathrm{p}<0.01,{ }^{\mathrm{t}} \mathrm{p}<0.001$

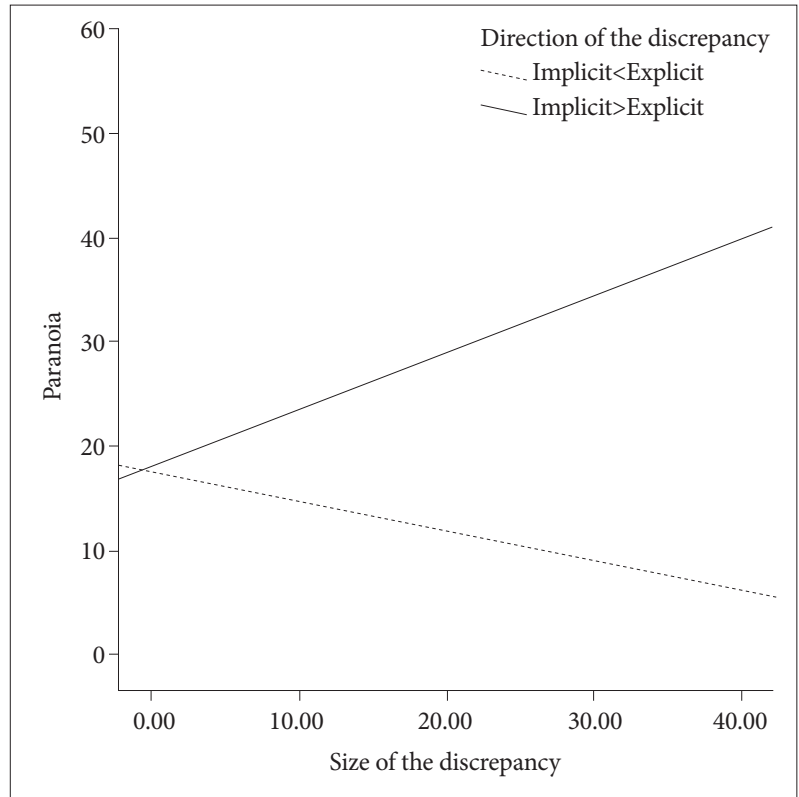

Figure 2. Predicted values for paranoia, illustrating the interaction between the size of the discrepancy and the direction of the discrepancy.

plicit self-esteem was negatively associated with subclinical paranoia, as well as blame bias and hostility perception bias in ambiguous situations, whereas no associations was found for implicit self-esteem. The interaction between implicit and explicit self-esteem was associated with hostility bias in ambiguous situations. Furthermore, the size of the discrepancy between the two self-esteems was positively associated with hostility perception bias in ambiguous situations. The socalled damaged self-esteem (high implicit and low explicit selfesteem) was positively associated with blame bias and hostility perception bias in ambiguous situations and subclinical paranoia. Importantly, these findings indicate that larger discrepancy in damaged self-esteem may be underlie the tendency to blame others and perceive hostility in ambiguous situations.

First, the explicit self-esteem showed negative correlation to subclinical paranoia and blame bias and hostility perception bias in ambiguous situations. Our findings on the relationship of explicit self-esteem with paranoia is in line with previous studies that reported low explicit self-esteem to be associated with paranoia in both clinical ${ }^{42}$ and non-clinical groups. ${ }^{43-45}$ In addition to these findings, our study is the first to show the association of low explicit self-esteem to the attributional bias. Previous studies on the attributional bias showed blaming and hostility perception bias in ambiguous situations to be most strongly and consistently associated with paranoia among all the items of the AIHQ. ${ }^{38,46}$ Current findings support the role of low explicit self-esteem in the generation of the attributional bias that may be a precursor to paranoia.

Second, the relationship of implicit self-esteem with sub- 
clinical paranoia and attributional bias was examined. Findings showed no association of implicit self-esteem with paranoia nor any of the variables of the AIHQ. This is in line with previous studies such as that of Kesting et al. ${ }^{11}$ and MacKinnon et al. ${ }^{12}$ which showed comparable implicit self-esteem in patients with persecutory delusions compared to controls. However, some previous studies reported lower implicit selfesteem in the paranoid patient group compared to the controls. ${ }^{8-10}$ Mixed results leave the role of implicit self-esteem as yet elusive, but we may cautiously consider that lower implicit self-esteem alone may not directly contribute to the hostile perception or blaming bias that may lead to paranoia and formation of delusions.

Third, we found that the interaction between implicit and explicit self-esteem was associated with hostility perception bias in ambiguous situations. Specifically, when participants reported low explicit self-esteem, their implicit self-esteem was positively related to perceived hostility in ambiguous situations. This is an important finding as it emphasizes the importance to study the discrepancy between implicit and explicit self-esteem in order to understand the role of implicit self-esteem in the attributional bias. To our knowledge, this is the first study that investigated the association of the interaction of implicit and explicit self-esteem with the biased attributional style.

The current study explored whether the discrepancy between implicit and explicit self-esteem predicts the attributional bias and paranoia. The size of discrepancy was positively related to hostility perception in ambiguous situations. The finding indicated that with larger discrepancy between implicit and explicit self-esteem, the likelihood to perceive hostility in ambiguous situations increases. Moreover, regarding the direction of the discrepancy, current study found damaged self-esteem (high implicit and low explicit self-esteem) to be associated with higher tendency to blame others and perceive hostility in ambiguous situations. Also, the size and the direction of the discrepancy had a significant interaction effect, showing that individuals with larger discrepancy between high implicit self-esteem and low explicit self-esteem exhibit more subclinical paranoia. While few previous studies on the self-esteem discrepancy in clinical patients examined categorical group differences compared to healthy controls or other clinical controls (e.g., depressed patients) focusing solely on paranoia, ${ }^{11,18,19}$ current study was able to investigate the effect of the size and the direction of the discrepancy and the interaction between the two on subclinical paranoia, as well as on the attributional bias, in a dimensional manner. Studies examining the effect of size and the direction of the self-esteem discrepancy in both paranoia and attributional bias in the clinical population will be needed in the future.
Hypothetically, individuals with damaged self-esteem with its high explicit self-esteem may have high expectations for oneself. However, if this is not met in reality, those with damaged self-esteem may engage in excessive attribution to others for negative outcomes and perceive more hostility.

There are some limitations to the present study. First, the sample consisted only of healthy young woman, although the sample size was relatively larger compared to previous studies. Future research should examine whether our findings can be generalized to other groups. Secondly, this was a cross-sectional study and thus was unable to explore the causality between the associations of self-esteem, attributional bias and paranoia. Furthermore, it has been reported that self-esteem may vary across time: future studies with a longitudinal design will provide important information. Lastly, implicit selfesteem is a complex and multidimensional construct that can show several different aspects depending on measurement tools. ${ }^{47}$ IAT is considered to be one of the best measures available for implicit self-esteem, but additional tools may aid to show differential findings and add to the understanding such a complex system.

The current study provides several significant insights for future research. Although there have been many studies on explicit self-esteem measured by self-reports, there have been few studies on the implicit self-esteem and even more scarce on the size and the direction of the discrepancy between the two self-esteems. Current findings suggest the need for further investigation of the effects of self-esteem discrepancy on paranoia and attributional bias and direct future research to re-evaluate the conceptual models that only include external or implicit self-esteem alone.

\section{Acknowledgments}

This study was supported by a grant of the Korea Mental Health Technology R\&D Project, Ministry of Health \& Welfare, Republic of Korea (Grant number: HM16C1991).

\section{REFERENCES}

1. Kinderman P, Bentall RP. Self-discrepancies and persecutory delusions: evidence for a model of paranoid ideation. J Abnorm Psychol 1996;105:106-113.

2. Kinderman P, Bentall RP. Causal attributions in paranoia and depression: Internal, personal, and situational attributions for negative events. J Abnorm Psychol 1997;106:341-345.

3. Rosenberg M. Society and the Adolescent Child. Princeton, NJ: Princeton University Press; 1965.

4. Bentall RP, Kinderman P, Kaney S. The self, attributional processes and abnormal beliefs: towards a model of persecutory delusions. Behav Res Ther 1994;32:331-341.

5. Garety PA, Freeman D. Cognitive approaches to delusions: a critical review of theories and evidence. Br J Clin Psychol 1999;38:113-154.

6. Freeman D, Garety PA, Kuipers E, Fowler D, Bebbington PE. A cognitive model of persecutory delusions. Br J Clin Psychol 2002;41:331-347.

7. Tiernan B, Tracey R, Shannon C. Paranoia and self-concepts in psychosis: a systematic review of the literature. Psychiatry Res 2014;216:303-313. 
8. Moritz S, Werner R, Collani Gv. The inferiority complex in paranoia readdressed: a study with the Implicit Association Test. Cogn Neuropsychiatry 2006;11:402-415.

9. McKay R, Langdon R, Coltheart M. The defensive function of persecutory delusions: an investigation using the Implicit Association Test. Cogn Neuropsychiatry 2007;12:1-24.

10. Valiente C, Cantero D, Vázquez C, Sanchez Á, Provencio M, Espinosa R. Implicit and explicit self-esteem discrepancies in paranoia and depression. J Abnorm Psychol 2011;120:691-699.

11. Kesting ML, Mehl S, Rief W, Lindenmeyer J, Lincoln TM. When paranoia fails to enhance self-esteem: explicit and implicit self-esteem and its discrepancy in patients with persecutory delusions compared to depressed and healthy controls. Psychiatry Res 2011;186:197-202.

12. MacKinnon K, Newman-Taylor K, Stopa L. Persecutory delusions and the self: An investigation of implicit and explicit self-esteem. J Behav Ther Exp Psychiatry 2011;42:54-64.

13. Clark LA, Cuthbert B, Lewis-Fernández R, Narrow WE, Reed GM. Three approaches to understanding and classifying mental disorder: ICD-11, DSM-5, and the National Institute of Mental Health's Research Domain Criteria (RDoC). Psychol Sci Public Interest 2017;18:72-145.

14. Freeman D. Suspicious minds: the psychology of persecutory delusions. Clin Psychol Rev 2007;27:425-457.

15. Klein HS, Kelsven S, Pinkham AE. Increased social cognitive bias in subclinical paranoia. Schizophr Res Cogn 2018;12:74-76.

16. Buck BE, Pinkham AE, Harvey PD, Penn DL. Revisiting the validity of measures of social cognitive bias in schizophrenia: additional results from the Social Cognition Psychometric Evaluation (SCOPE) study. Br J Clin Psychol 2016;55:441-454.

17. Pinkham AE, Harvey PD, Penn DL. Paranoid individuals with schizophrenia show greater social cognitive bias and worse social functioning than non-paranoid individuals with schizophrenia. Schizophr Res Cogn 2016;3:33-38.

18. Vázquez C, Diez-Alegría C, Hernández-Lloreda MJ, Moreno MN. Implicit and explicit self-schema in active deluded, remitted deluded, and depressed patients. J Behav Ther Exp Psychiatry 2008;39:587-599.

19. Nakamura M, Hayakawa T, Okamura A, Kohigashi M, Fukui K, Narumoto J. Defensive function of persecutory delusion and discrepancy between explicit and implicit self-esteem in schizophrenia: study using the Brief Implicit Association Test. Neuropsychiatr Dis Treat 2015;11: 33-40.

20. Bosson JK, Swann Jr WB, Pennebaker JW. Stalking the perfect measure of implicit self-esteem: the blind men and the elephant revisited? J Pers Soc Psychol 2000;79:631-643.

21. Schröder-Abé M, Rudolph A, Wiesner A, Schütz A. Self-esteem discrepancies and defensive reactions to social feedback. Int J Psychol 2007; 42:174-183.

22. Bosson JK, Brown RP, Zeigler-Hill V, Swann WB. Self-enhancement tendencies among people with high explicit self-esteem: the moderating role of implicit self-esteem. Self Identity 2003;2:169-187.

23. Jordan CH, Spencer SJ, Zanna MP, Hoshino-Browne E, Correll J. Secure and defensive high self-esteem. J Pers Soc Psychol 2003;85:969978.

24. Rosenberg M. Conceiving the Self. 1979. New York: Basic; 1979.

25. Lee JY, Nam SK, Lee MK, Lee JH, Lee S. Rosenberg'self-esteem scale: analysis of item-level validity. Korean J Couns Psychother 2009;21:173189.

26. Greenwald AG, McGhee DE, Schwartz JL. Measuring individual differences in implicit cognition: the implicit association test. J Pers Soc Psychol 1998;74:1464-1480.

27. Greenwald AG, Nosek BA, Banaji MR. Understanding and using the implicit association test: I. An improved scoring algorithm. J Pers Soc Psychol 2003;85:197-216.

28. Risch AK, Buba A, Birk U, Morina N, Steffens MC, Stangier U. Implicit self-esteem in recurrently depressed patients. J Behav Ther Exp Psychiatry 2010;41:199-206.

29. Hofmann W, Gawronski B, Gschwendner T, Le H, Schmitt M. A metaanalysis on the correlation between the Implicit Association Test and explicit self-report measures. Pers Soc Psychol Bull 2005;31:1369-1385.

30. Steffens MC, Kirschbaum M, Glados P. Avoiding stimulus confounds in Implicit Association Tests by using the concepts as stimuli. Br J Soc Psychol 2008;47:217-243.

31. Steffens MC. Is the implicit association test immune to faking? Exp Psychol 2004;51:165-179.

32. Greenwald AG, Farnham SD. Using the implicit association test to measure self-esteem and self-concept. J Pers Soc Psychol 2000;79:10221038.

33. Hong YO, Lee HK. Measurement of regional prejudice by implicit association test. Korean J Soc Pers Psychol 2001;15:185-204.

34. Banaji MR. Implicit Attitudes Can be Measured. In: Roediger HL, Airne JS, Neath I, Surprenant A, Editors. The Nature of Remembering: Essays in Honor of Robert G. Crowder. Washington, DC: American Psychological Association, 2001, p.117.

35. Roefs A, Huijding J, Smulders FT, MacLeod CM, de Jong PJ, Wiers RW, et al. Implicit measures of association in psychopathology research. Psychol Bull 2011;137:149-193.

36. Nosek BA, Greenwald AG, Banaji MR. Understanding and using the Implicit Association Test: II. Method variables and construct validity. Pers Soc Psychol Bull 2005;31:166-180.

37. Lee HJ, Won HJ. A study of the reliability and the validity of the paranoia scale. Korean J Clin Psychol 1995;14:83-94.

38. Combs DR, Penn DL, Wicher M, Waldheter E. The Ambiguous Intentions Hostility Questionnaire (AIHQ): a new measure for evaluating hostile social-cognitive biases in paranoia. Cogn Neuropsychiatry 2007;12:128-143.

39. Chang H, Lee SK, Kim KR, Lee SY, Park JY, Kim EJ, et al. Development of Korean version of the ambiguous intentions Hostility Questionnaire (K-AIHQ). J Korean Neuropsychiatr Assoc 2009;48:29-35.

40. Aiken LS, West SG, Reno RR. Multiple Regression: Testing and Interpreting Interactions. Newbury Park: Sage; 1991.

41. Brinol P, Petty RE, Wheeler SC. Discrepancies between explicit and implicit self-concepts: consequences for information processing. J Pers Soc Psychol 2006;91:154-170.

42. Freeman D, Garety P, Fowler D, Kuipers E, Dunn G, Bebbington P, et al. The London-East Anglia randomized controlled trial of cognitivebehaviour therapy for psychosis IV: Self-esteem and persecutory delusions. Br J Clin Psychol 1998;37:415-430.

43. Combs DR, Penn DL. The role of subclinical paranoia on social perception and behavior. Schizophr Res 2004;69:93-104.

44. Ellett L, Lopes B, Chadwick P. Paranoia in a nonclinical population of college students. J Nerv Ment Dis 2003;191:425-430.

45. Martin JA, Penn DL. Social cognition and subclinical paranoid ideation. Br J Clin Psychol 2001;40:261-265.

46. Combs DR, Penn DL, Michael CO, Basso MR, Wiedeman R, Siebenmorgan $\mathrm{M}$, et al. Perceptions of hostility by persons with and without persecutory delusions. Cogn Neuropsychiatry 2009;14:30-52.

47. Koole SL, Pelham BW. On the Nature of Implicit Self-Esteem: The Case of the Name Letter Effect. In: Spencer SJ, Fein S, Zanna MP, Olson JM, Editors. Motivated Social Perception: The Ontario Symposium, Vol. 9. Mahwah: Lawrence Erlbaum Associates, Inc., 2003, p.93-116. 